\title{
Rapid prototyping by heat diffusion of metal foil and related mechanical testing
}

\author{
Javaid Butt $^{1} \cdot$ Habtom Mebrahtu ${ }^{1} \cdot$ Hassan Shirvani ${ }^{1}$
}

Received: 16 January 2015 / Accepted: 21 September 2015 /Published online: 1 October 2015

(C) The Author(s) 2015. This article is published with open access at Springerlink.com

\begin{abstract}
Rapid prototyping has made massive strides in the technological industries and is at the fore front of innovation. However, the majority of these methods use different types of plastic and other materials including resins and flour, for the production of prototypes. They can only be used as visual prototypes in most instances and do not provide sufficient information for direct material testing which is needed to understand the mechanical properties for large-scale production. The current methods employing powder metals have their limitations and are very expensive. There is an emphasis on the production of metal parts because they provide an environment for testing rather than approximations and usually give more insight into the design parameters. This research presents a new rapid prototyping process for the production of high-quality metal parts that can be used after production with minimal post-processing. The process is a combination of laminated object manufacturing and soldering techniques. The process is referred to as composite metal foil manufacturing, and its effectiveness is validated with lap-shear testing, peel testing, microstructural analysis and comparative studies. Specimens were produced using copper foils of $100-\mu \mathrm{m}$ thickness. The results obtained have been promising demonstrating that the process is not only capable of producing metal parts efficiently but can also produce stronger parts compared to traditional methods. This shows that the proposed process
\end{abstract}

Javaid Butt

javaid.butt@student.anglia.ac.uk

Habtom Mebrahtu

habtom.mebrahtu@anglia.ac.uk

Hassan Shirvani

hassan.shirvani@anglia.ac.uk

1 Engineering \& Built Environment, Anglia Ruskin University, Bishop Hall Lane, Chelmsford CM1 1SQ, UK has the capability to be a strong candidate in the field of metal prototyping.

Keywords Rapid prototyping · Laminated object manufacturing $\cdot$ Metal parts · Metal foil - Rapid prototyping . Soldering

\section{Introduction}

Rapid prototyping (RP) is a term that is referred to a group of technologies that produce three-dimensional objects from computer-aided design (CAD) data [1,2]. These technologies are considered to be the future of manufacturing, and it is largely due to the production of parts from a range of materials including plastics, ceramics and metals. Metal prototyping is highly valued in the technological market because metal parts give conclusive results as to how a part would behave in a particular situation. There are a couple of rapid prototyping technologies capable of producing metal parts, namely, direct metal laser sintering (DMLS) and electron beam melting (EBM). DMLS has significant advantages such as geometrical complexity, near net shape, low energy consumption and high raw material utilization [3]. But, as long as the list of advantages is, there is an even longer list of disadvantages including choice of materials, build speed, stress concentrations, surface finish and poor mechanical properties of the parts produced $[4,5]$. EBM lies in the same category as DMLS with a list of advantages including inexpensive consumables, vacuum build atmosphere, minimal stress induced during build and elevated build temperatures. However, it is not without challenges either that include the availability of materials, powder removal, build speed and surface finish [6-10]. There is another method that was proposed to build metal parts using 
metal foils, and it combines laminated object manufacturing (LOM) with diffusion welding, but the setup is expensive and poses operating issues [11]. It cannot work with thicknesses less than $0.5 \mathrm{~mm}$ as anything less than that results in staircase effect. The process also requires the generation of contours that require a sufficient self-stiffness of the sheets, and anything less than $0.5 \mathrm{~mm}$ results in failure of the contour generation. The surface quality is not good, and the products require post-processing such as milling, build-up welding, or shot peening if necessary [12].

These are serious problems and need to be addressed to devise a process capable of overcoming them. The paper presents a novel rapid prototyping process that solves most of the mentioned problems and also offers simplicity to its end users. The proposed process is named as composite metal foil manufacturing (CMFM) and is a combination of LOM and soldering technologies. These two processes have been around for decades but never integrated together for the production of metal parts. CMFM combines the simplicity of LOM with the flexibility of soldering that makes it a very feasible process [13]. The material selection for prototyping was driven by the ease of soldering for metal foils. Metals like aluminium and stainless steel are among the most difficult to solder because of their tenacious oxide layer, and the research intends to cover aluminium alloys in the future. But, at this stage, to demonstrate the process, a material of good solderability, copper, has been used. Parts were produced using this process from copper foils of $100-\mu \mathrm{m}$ thickness and tested according to British and international standards. There is no need for any post-processing, and the products made by the proposed process have good surface finish. The product is actually the metal itself, and it keeps all the properties of the parent metal from which it is produced. The process has a significantly shorter production time. When the 3D Slicer is busy slicing the CAD model, the plates are being heated up so that no time is wasted once the solder-coated foils are ready to be joined. The dispenser is a state-of-the-art equipment and can move at various speeds depending on the amount of paste it is dispensing. Since the plates were already set up to heat, after stacking the foils the joining operation can be carried out straight away without any delay. Both plates heat up the product and, depending on its thickness, time of heating varies.

The process uses pressure and heat from the plates for final joining. The application of pressure during the heating is important for two reasons (1) to have a uniform layer of consistent thickness and (2) to join the metal foils together. The paste becomes liquid on reaching its melting point and, at that time, the pressure applied helps the paste to cut through the oxide layer. This could be seen as a drawback of the process as it would hinder the production of certain types of products (e.g., circular shaped). The process is fully capable of manufacturing parts and/or products that are hollow or irregular shaped and have uniform or varying cross sections, structures with overhanging elements, etc. Thermal stresses are also generated due to the application of heat, but they are not as significant as to damage the mechanical properties of the product being produced. The process is aimed for the production of metal parts and products that can be used directly after production with minimal post-processing.

Section 2 describes the details of the proposed process along with the practices that were utilized for the production of parts. Section 3 explains the tests that were performed to assess the effectiveness of the process with the results and discussion explained in Sect. 4 followed by the potential of application and conclusions.

\section{Composite metal foil manufacturing process design}

\subsection{Proposed process details}

The main components of the process are a feed mechanism that advances a metal sheet over a build platform, a laser to cut the outline of the part in each sheet layer, a dispenser that dispenses solder paste on the metal sheets, a roller that smoothes the paste into a uniform layer, two laser sensors for measuring the thickness of the part at all times, a heated plate to apply pressure and heat to bond the solder-coated sheets together to produce the final product. Figure 1 shows the conceptual model of the machine based on the principle of composite metal foil manufacturing.

The process can be divided into two stages with the first involving stacking while the second stage is the joining operation to produce the final product. A block diagram of the whole procedure is shown in Fig. 2.

For the automated stacking of metal foils for threedimensional parts, a 3D CAD model of the part is necessary. The solid model design can be made in any commercial CAD software like ProE, SolidWorks, and AutoDesk Inventor. This model is first transferred to a set of two-dimensional layer data

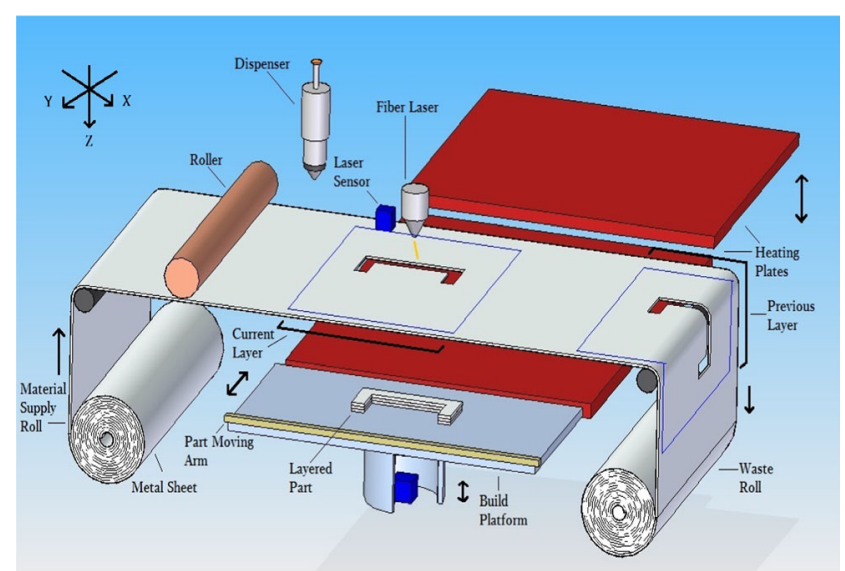

Fig. 1 Composite metal foil manufacturing process 
Fig. 2 Block diagram of CMFM

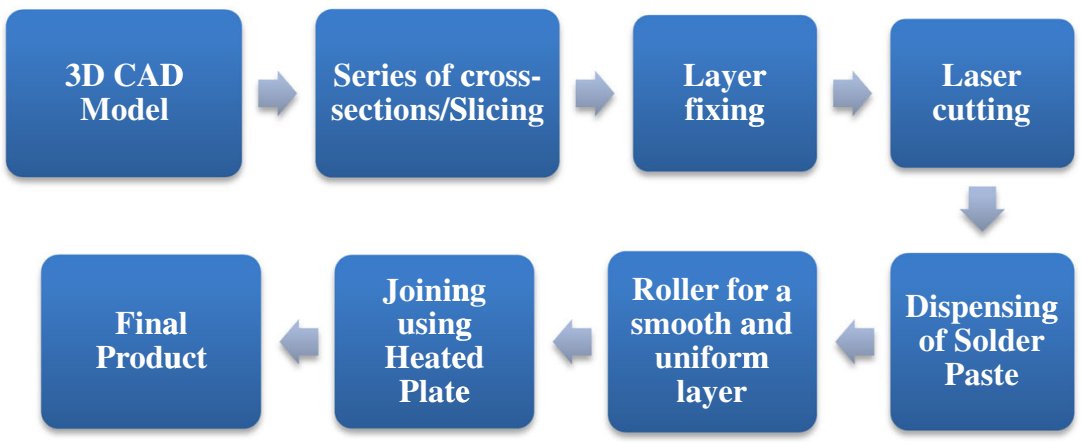

which includes the geometric information of the layer. It is achieved with the use of any commercial slicing software, and for this work, 3D Slicer was utilized. It creates layer data that is fed into the main program which then controls the flow of sheets from the material supply roll. The sheet metal comes in through the feed mechanism, and the laser cuts the outline of the part in the first layer. A 200-W fibre laser from MIYACHI is selected for this process as it has the capability of cutting metal sheets as thin as $50 \mu \mathrm{m}$ with high dimensional accuracy. Another advantage of using fibre laser is that it offers minimal thermal input, with fine control over how hot the work area gets. This is important because small parts heat up quickly and might otherwise overheat or deform. Fibre lasers are highly focusable to about $15 \mu \mathrm{m}$, which is about one sixth of the width of a strand of human hair. This makes it feasible to remove the minimum amount of material to make the cut, resulting in extremely high precision and accuracy. The laser operates automatically on receiving the layer data from the CAD model.

The process is slightly different when it comes to fixing the first layer. After the outline cutting of the first layer, the dispenser dispenses solder paste on it according to the defined geometry and the platform stays at its original position. The feed mechanism moves upward and moves the remaining of the sheet to the waste take-up roll. Another sheet is then advanced on top of the previously deposited layer. It is placed on top of the first layer by the feed mechanism that is capable of moving up and down just like the build platform. Before the laser cutting, a roller rolls on the surface of the sheet to make a uniform layer of the paste between the first and second layer. Model 710 Automatic Applicator from Fusion Automation Inc. was chosen based on its ability to dispense precise and minute quantities of paste without any waste. This compact unit features adjustable time and pressure controls to provide paste deposit sizes ranging from small dots to continuous stripes of any length. Each paste deposit is precisely measured, ensuring controlled filler metal costs without waste. The amount and time of dispensing are based on the geometric features of the layers.

The heat produced during the cutting process melts the solder paste at the edges that keeps the two foils in perfect alignment. The platform is then moved down according to the thickness of the foils and the solder layer between them. The thickness is measured by two laser sensors that send the information to the system so that no error occurs in lowering the platform. The next sheet then comes in and the platform moves upwards. The laser cuts the outline which again melts the paste at the edges. The process goes on until all the sheets have been cut and deposited with solder paste. If the extra material is allowed to stay in place, then it would be an extremely difficult post-processing operation to remove the unwanted metal from the desired part. The measurement of thickness during the process is an important aspect as it ensures dimensional accuracy of the part being produced. The Microtrak $^{\mathrm{TM}} 3$ TGS system is designed specifically for thickness applications. The product can easily interface with PLCs and PCs or can be used in a stand-alone configuration. Each module contains an integral LCD display and keypad for setting up and visual display of measurements. Basic input/ output is provided by discrete lines or a serial interface configured as Modbus ${ }^{\circledR}$ RTU over RS-485 or RS-232. The two sensors are mounted on either sides of the platform to ensure accuracy in thickness measurement. The sensors have a measuring accuracy of $\pm 1-1270 \mathrm{~mm}$ and a measuring speed of $9400 \mathrm{~Hz}$.

After the cutting, dispensing and stacking have been done, a stacked structure of solder-paste-coated layers is left behind. The structure is stable enough to be moved and so an arm moves the structure onto the heated plate. It is then heated from top and bottom by a heated plate that applies pressure and heat to produce the product. It is important to describe the solder paste being utilized as it is majorly responsible for the joining operation. The solder paste is known as direct aluminium soldering paste (AL27-103-75) and is a product of Superior Flux \& Manufacturing Company. It is made from Type 3 Powder (-325/+500 Mesh Powder) with a unique flux binding system to keep the very active aluminium flux portion of the flux form degrading the solder powder. The paste utilizes a water-soluble chemistry so cleaning involves simply rinsing in hot water. The material should be refrigerated before use and when in storage. The temperature for printing and dispensing the paste is $20-23{ }^{\circ} \mathrm{C}$ with $35-55 \%$ of relative 
humidity. The paste is $96.5 / 3.5$ tin/silver consisting of a special flux medium and lead-free solder alloy. It has a soldering range of $280-380^{\circ} \mathrm{C}$. However, it should not be kept at the maximum temperature for more than $8 \mathrm{~min}$ as after this time the paste stops working. The heating plates are set to a temperature of $350{ }^{\circ} \mathrm{C}$ so as to allow for quick heating of the product. They apply heat and pressure - both are essential to ensure proper bonding and dimensional accuracy. The plates are of stainless steel and are fitted with FIREROD cartridge heaters from Watlow and can go up to a maximum of $550^{\circ} \mathrm{C}$.

The above explanation describes the process as a whole, but the research was carried out by breaking down the process into independent steps that were performed to make products. The next section explains the main steps and the methods used to prove the process.

\subsection{Experimental setup}

The process is complex and needed to be broken down into simple steps for practicality; thus, an experimental setup was created to demonstrate the capability of the process. It was important to make sure that the process utilizes the minimum resources as one of the objectives is to make this process as cost-effective as possible. As the process of soldering can be tricky for certain metals, it was necessary to make the process as adaptable as possible so that it can handle difficult metals.

Copper foils (99.9 \% pure copper) were used for the process and were cut according to the dimensions of the desired specimen. Solder paste was deposited manually, and after the deposition of paste, the specimen was placed between two stainless steel plates fitted with nuts and bolts. The entire structure (solder-coated foils and plates) was placed inside a furnace. It was allowed to be heated for a set time depending on the type of specimen and then taken out. After cooling, the specimen was ready for testing as there is no post-processing involved.

\section{Experimental methodology}

Lap-shear, peel test, microstructural analysis and comparative analysis were carried out to assess the effectiveness of the proposed process. Specimens were produced using $99.9 \%$ pure copper foils (BS EN 13599:2002) with a thickness of $100 \mu \mathrm{m}$, and they were used as supplied with no surface treatment. A special solder paste was utilized for bonding purposes. Tests were carried out in accordance with British and international standards where applicable.

\subsection{Tensile lap-shear test}

There is no lap-shear testing standard for foils at $100 \mu \mathrm{m}$, but the BS EN 1465: 2009 [14] was followed where possible even though it relates to thicker foils of metal $(1.6 \pm 0.1 \mathrm{~mm})$. The Hounsfield Tinius Olsen Tensile Testing Machine was used for carrying out the lap-shear testing. The machine was operated at a speed of $100 \mathrm{~mm} / \mathrm{min}$ with the $200-\mathrm{mm}$-long and 25 mm-wide specimens at an overlap length of $12.5 \mathrm{~mm}$ (Fig. 3).

\subsection{Peel test}

The peel test was performed in accordance with BS EN ISO 11339:2010 [15], which was designed for the determination of the strength of adhesives on flexible-to-flexible bonded assemblies based on the maximum load specimens can withstand under peeling action. The specimens were $200 \mathrm{~mm}$ long and $25 \mathrm{~mm}$ wide. Out of the $200-\mathrm{mm}$ length, $150 \mathrm{~mm}$ was bonded with the solder paste (Fig. 4).

\subsection{Microstructural analysis}

The aim of the microstructural analysis was to establish the proportion of bonded to unbounded area in a specimen. This means that the higher the proportion of the soldered zone, the stronger the bond and vice versa. For cross-sectional analysis, specimens were cut from the centre portion (approximately $20 \mathrm{~mm}$ from where the soldered zone commenced). Every specimen was polished with sand paper and then dipped in a solution of alcoholic acidified ferric chloride solution for a few seconds [16]. It was then mounted on the platform of the scanning electron microscope (SEM).

\subsection{Tensile testing for dog-bone specimen}

A dog-bone specimen was produced by following BS EN ISO 6892-1: 2009 [17]. The specimen (composite copper) produced by CMFM was first tested and was then compared to the same shaped specimen machined out of a copper block. Both the specimens were $2.7 \mathrm{~mm}$ thick, $87.5 \mathrm{~mm}$ long and $12.5 \mathrm{~mm}$ wide and had a gauge length of $50 \mathrm{~mm}$ (Fig. 5). The composite copper (specimen produced by CMFM) was made up of 14 layers stacked on top of each other with a uniform bond thickness of $0.1 \mathrm{~mm}$.

\section{Results and discussion}

\subsection{Results from lap-shear test}

From the specimens tested, all broke within the base metal adjacent to the bonded area (Fig. 6). In none of the specimens did breaks occur within the soldered area/zone. As in tensile testing, specimens failed at locations with minimum crosssectional area (i.e., the base metal, instead of the lapped region which had twice the cross-sectional area). 

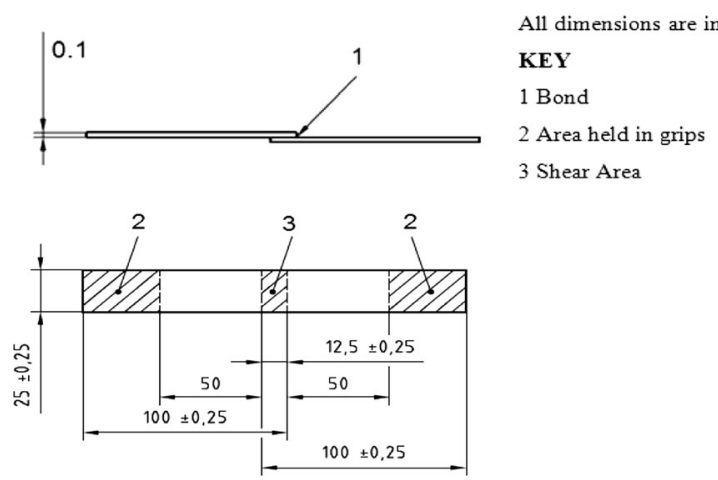

Fig. 3 Dimensions of lap-shear specimen

The results show the effectiveness of the bond, and in all the specimens, the failure was recorded according to BS EN ISO 10365:1995 [18]. The failure pattern was always substrate failure with the designation SF. There are a number of factors that can affect the outcome of the test results. They include lap joint length, gage length and asymmetric loading. To make sure that repeatability was observed in the test results, careful measures were taken. The lap joint was kept at a length of $12.5 \mathrm{~mm}$ according to the standard. The test specimens were symmetrically placed in the grips, with each grip $50 \pm 1 \mathrm{~mm}$ from the nearest edge of the overlap. Additional foils were used in the grips so that the applied force will be in the plane of the bond. Figure 7 shows the test results of the lap-shear specimens.

\subsection{Results from peel test}

The peel test was found to be effective in determining the bond effectiveness. From the specimens tested, two categories of failure mode were observed (Fig. 8).

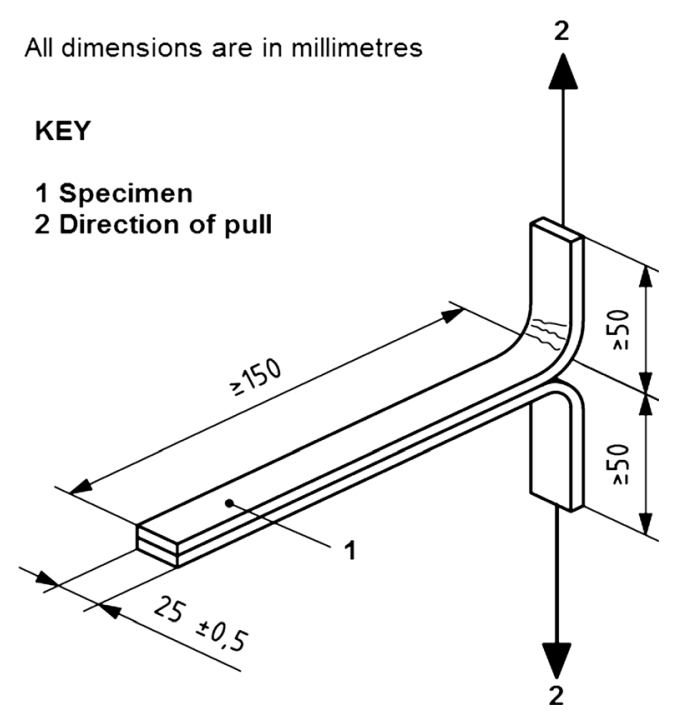

Fig. 4 Dimensions of peel test specimen

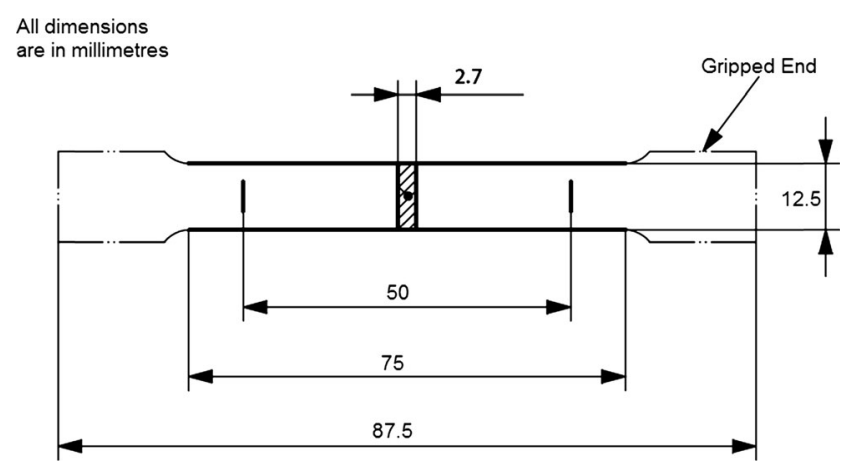

Fig. 5 Dimensions of the dog-bone specimen

The two failure modes were (Fig. 9) as follows:

1. Where there was a clear break at the beginning of a soldered region (when a load was applied) indicating an effective bond giving a high load ranging from 382 to $432 \mathrm{~N}$.

2. Where a sample did not break at the beginning of soldered region but failed as the breaking points grew under loading. Typically, such failure resulted in soldered loads of around $337 \mathrm{~N}$.

The peel test used in the experiments did not behave in the same way as a peel test applied to adhesive bonds which tend to fail uniformly across the bond interface. When applied to soldered specimens, the method of failure was different and tended to propagate from a series of 'contact points'. A contact point is defined as a small region within the soldered zone that was fully bonded. Under peeling action, a contact point remains bonded with un-bonded material around it tearing during failure to give the effect of 'teeth'. The more contact points present in a soldered sample, the higher the resistance to peeling with shorter teeth being observed. This indicated that even though soldering was done, there may still be regions where no atomic bond was present either through insufficient force being applied or through the presence of oxide at the interface. The peel test results were essentially a qualitative measure of
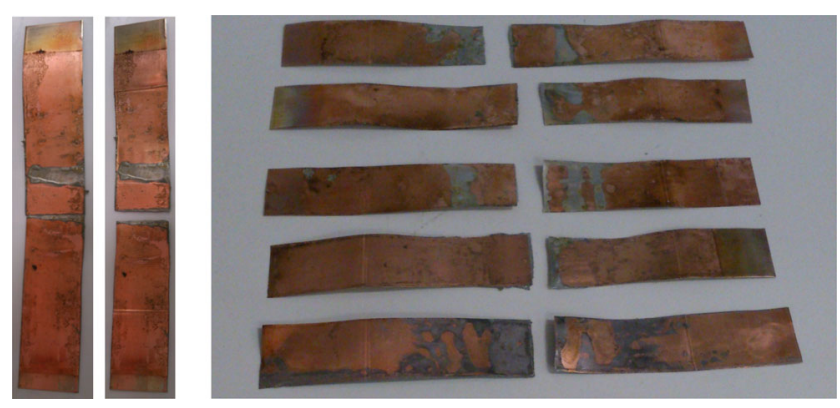

Fig. 6 Failure modes of copper lap-shear specimens 


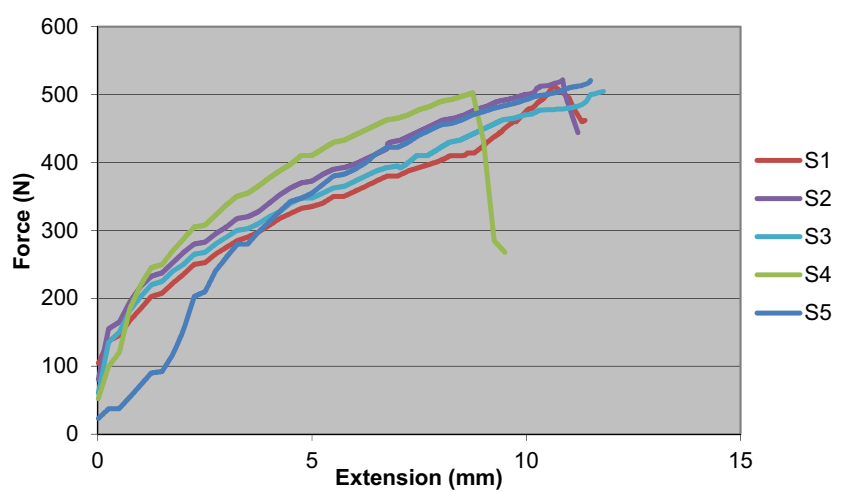

Fig. 7 Lap-shear test results

failure of the many contact points within a soldered interface (with contact points failing at differing loads). However, the test proved useful as an indication of overall soldering effectiveness and did produce a proportional load response. In all the specimens, the failure was recorded according to BS EN ISO 10365:1995. The failure pattern was always delamination failure with the designation DF meaning that the substrate failed by splitting in layers.

\subsection{Results from microstructural analysis}

This test was important to identify the proportion of bonded to unbounded area within the specimen. Figure 10 shows a foil of copper deposited with solder paste. It clearly indicates the presence of an intermetallic bond at the surface, thus proving that there is a great proportion of area where the paste has bonded with the metal.

There are, however, areas where cracks are present as shown in Fig. 11. These cracks can cause wetting issues which will lead to no-bonded zones in the specimen. This is not a good thing when talking about the integrity of the specimen produced. Such zones tend to give false readings and can cause abrupt failures.

One way of overcoming this issue is to make sure that there is a uniform layer of paste on the surfaces to be soldered so that when the solder paste starts to melt, it could easily wet the entire surface rather than just the areas where the paste is
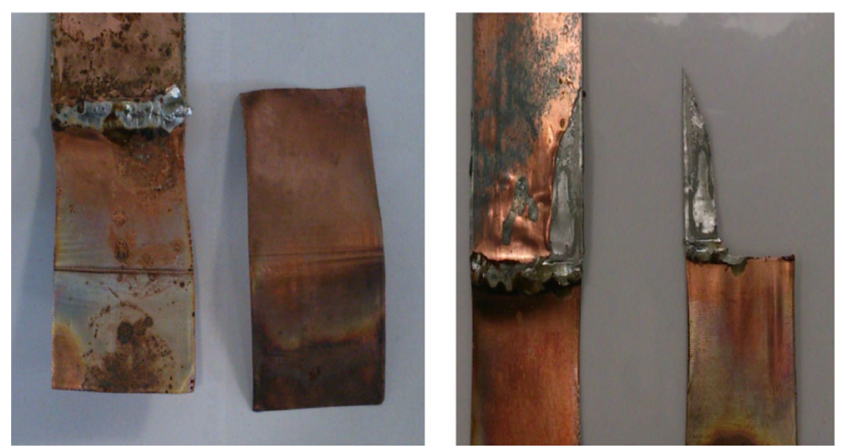

Fig. 8 Fracture modes of copper peel test

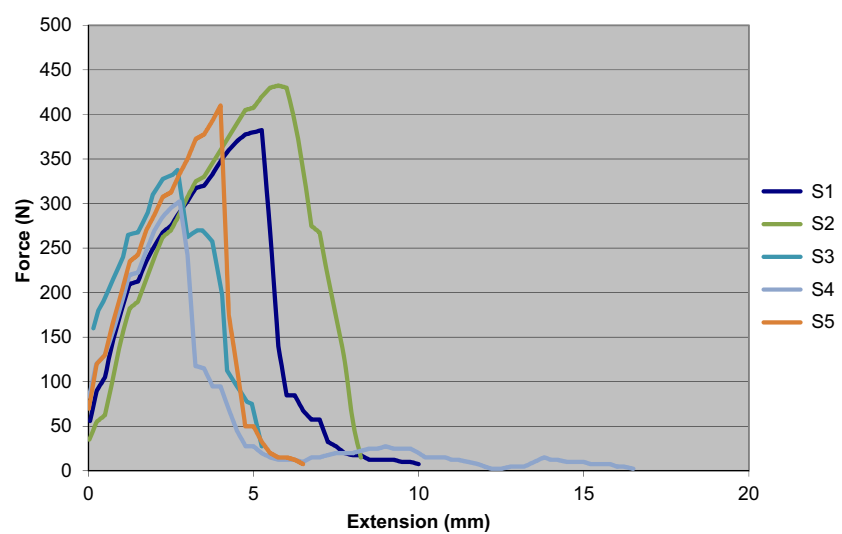

Fig. 9 T-peel test results

present. Copper has excellent solderability which helps the wetting process, but other factors need to be considered as well including applying appropriate pressure so that the molten paste seeps into the surface of the metal quickly and forms an intermetallic bond.

A sample was cut from a lap joint and was polished with sand paper. It was then dipped in a solution of alcoholic acidified ferric chloride solution for a few seconds. After drying, the sample was mounted on the platform of an optical microscope to see the lines of copper and solder. Figure 12 shows the cross section at 100 times magnification. The shiny yellowish lines indicate the copper metal whereas the black line in the middle indicates the solder.

\subsection{Results from dog-bone tensile test}

The test showed that the strength of the composite copper is higher than that of the parent copper. It shows the integrity of the bonding and the fact that the specimen produced by CMFM is much stronger than the product manufactured from traditional methods. Figure 13 shows the two specimens and Fig. 14 shows the comparison between the two specimens.

The maximum force for failure is $5550 \mathrm{~N}$ for the composite whereas it is $5000 \mathrm{~N}$ for the parent copper. There was no failure of individual layers but a complete failure of the specimen proving that the 14 layers that were bonded together were actually functioning as a single unit rather than individual layers and that added to the strength of the specimen. The reason for the high strength of copper is very basic. The yield strength of copper is $140 \mathrm{MPa}$ whereas the yield strength of the paste used is $40 \mathrm{MPa}$, and because the paste is forming an intermetallic bond with the metal, these strengths tend to add up theoretically [19]. As the number of layers increase, the strengths keep on adding theoretically. Practical testing does not show the same increase in strength as in theory but there is some addition in strength nonetheless which is evident from the Fig. 14. Furthermore, the layer of solder stops the metal atoms from slipping when stress is applied and thus prohibiting any dislocations. 


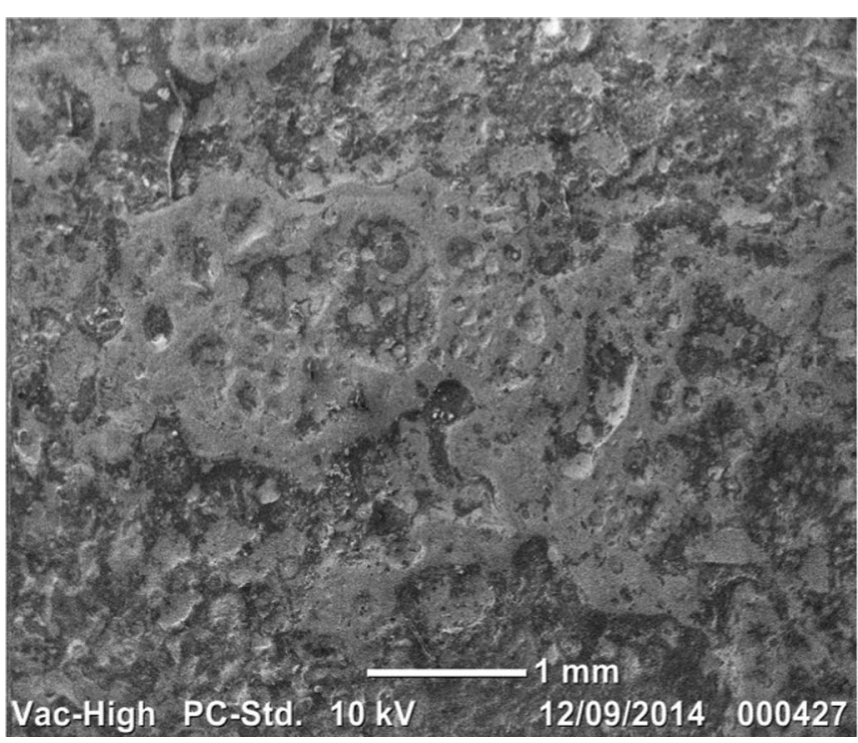

Fig. 10 SEM analysis of copper foil

Both the specimens follow the same elastic region and show almost identical behaviour. Copper being a ductile metal has a large plastic deformation range before fracturing whereas the composite copper does not behave in the same manner. It has high strength but a smaller plastic deformation range before fracturing due to the presence of intermetallic bonds among the layers. The bonds prevent the copper layers to follow their ductile nature resulting in a rather smaller plastic deformation range.

Copper being a ductile metal shows the presence of inclusions (Fig 15), which act as tiny stress concentrations. They either fracture or separate from the matrix, nucleating voids that grow and link up, ultimately causing fracture.

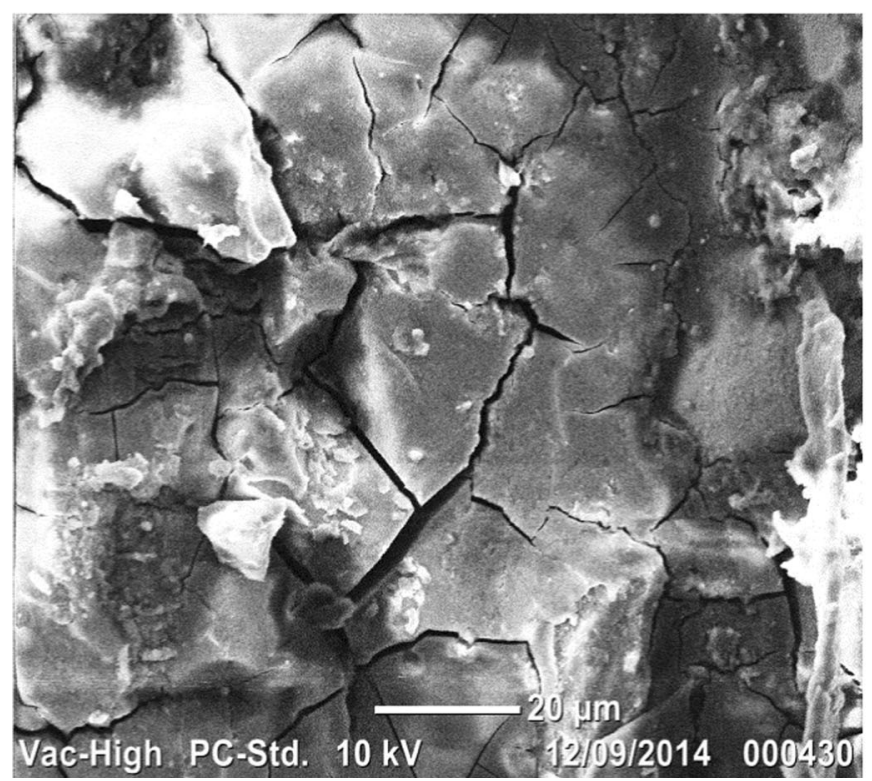

Fig. 11 SEM crack analysis of copper foil

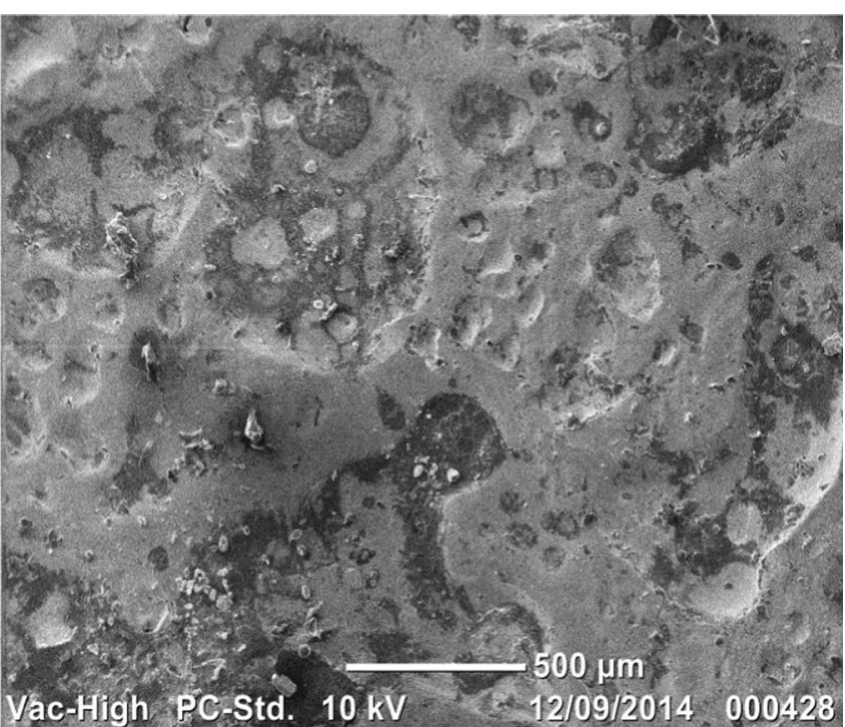

The composite copper has less pronounced fracture characteristics as compared to solid copper (Fig. 16) that allows it to have a smaller plastic deformation region.

The final products are layered structures of melted solder paste holding the metal foils together. The dimensional accuracy is largely dependent on the thickness of the foil and the paste. The thickness sensors give a very accurate reading, but when the foils are moved into the heating plates, then thermal stress and strain play a part as well. Experiments have shown that the accuracy of the final products is not affected to a great extent in the $\mathrm{X}$ and $\mathrm{Y}$ axes because the laser is responsible for cutting the outline of the part from a foil and the fibre laser being utilized has a high cut resolution of $50 \mu \mathrm{m}$. The

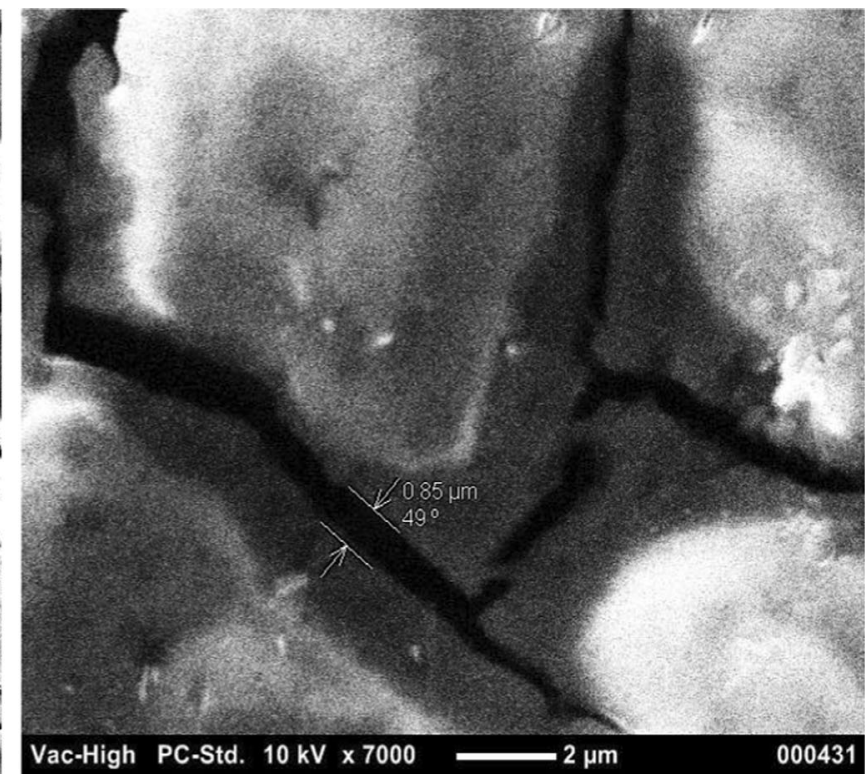




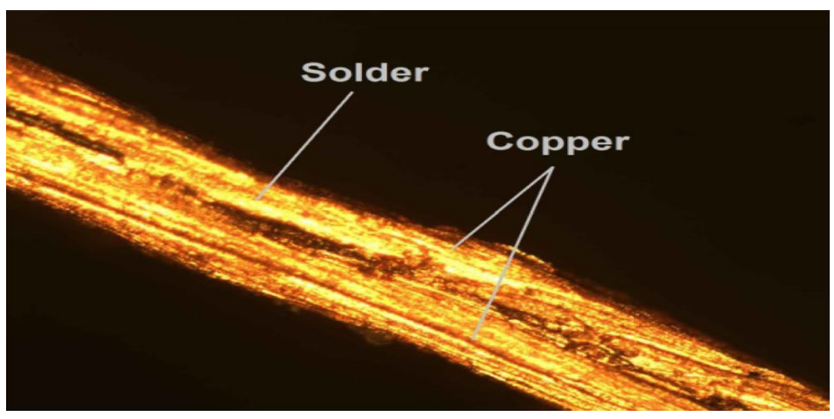

Fig. 12 Microscopic analysis of copper lap joint

accuracy in the vertical direction ( $\mathrm{Z}$ axis) depends on the layer thickness and is found to be $\pm 100 \mu \mathrm{m}$. On the other hand, as rival technologies like DMLS generates parts from metal powder, the surface roughness and the geometrical accuracy lie within the range of the powder grain size. The achievable part accuracy depends on which powder material is used, varying from about $\pm 50 \mu \mathrm{m}$ for Direct-Metal 20 to about $\pm 100 \mu \mathrm{m}$ for Direct-Steel 50. The resolution in the vertical direction (perpendicular to the layers) is determined by the layer thickness. For Direct-Metal 20, Direct-Steel 20 and Direct-Steel H20, it is typically $0.02 \mathrm{~mm}$; for Direct-Metal 50 and Direct-Steel 50, it is $0.05 \mathrm{~mm}$. For Direct-Metal 50 (grain size approximately $50 \mathrm{~mm})$, accuracies of $\pm(0.05 \%+50 \mathrm{~mm})$ are obtainable. Due to the slightly higher shrinkage during exposure and the smaller powder particle size, the obtainable accuracy for DirectMetal 20, Direct-Steel 20, Direct-Steel H20 and Direct-Steel is $50 \pm(0.07 \%+50 \mu \mathrm{m})$ [20].

For the DMLS process, the focussed laser beam with a diameter of approximately $0.4 \mathrm{~mm}$ is equivalent to the tool for fabricating the geometry. The sintering width is a little higher than the focal diameter due to heat conductivity effects. As with other processes, structures smaller than the used tool cannot be produced, although with DMLS the 'tool' size defines the minimum external feature size (e.g., wall thickness) rather than internal feature size (e.g., slot width). The minimum sintering width is approximately $0.6 \mathrm{~mm}$ for DirectMetal 20, $0.7 \mathrm{~mm}$ for Direct-Metal 50 and Direct-Steel 20, $0.8 \mathrm{~mm}$ for Direct-Steel H20 and $0.9 \mathrm{~mm}$ for Direct-Steel 50 . If structures smaller than this are contained in the geometry to be built, they cannot be built correctly. This must be considered carefully, especially for sharp corners and edges [21]. On the other hand, the fibre laser being utilized for CMFM is
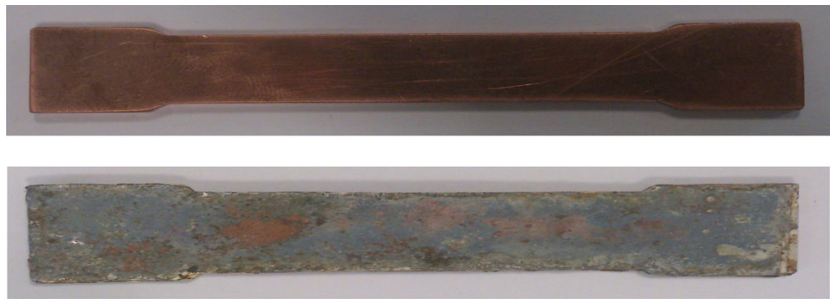

Fig. 13 Tensile test specimens

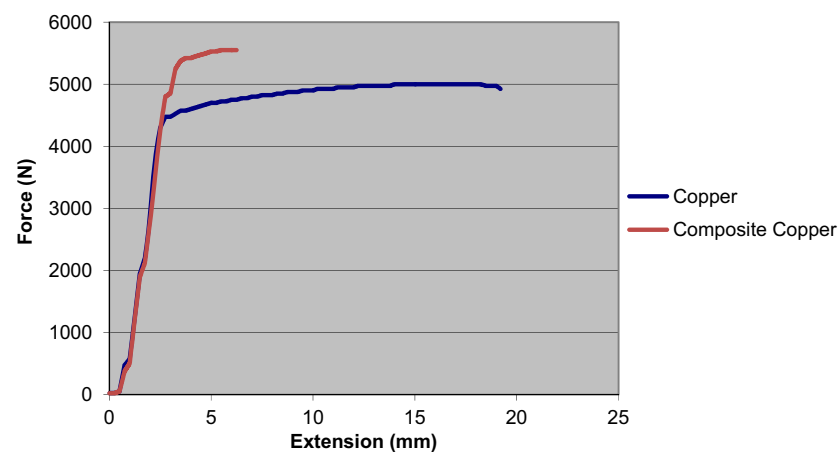

Fig. 14 Comparative tensile test

focusable to about $15 \mu \mathrm{m}$, resulting in extremely high precision and accuracy.

\section{Potential of application}

The process of composite metal foil manufacturing has the potential to be at the forefront of technological advancement for making prototypes for direct testing. This method could very well follow the same upwards trend that threedimensional (3D) printers have gone through over the past few years. Similar to 3D printers that have become a craze owing to the simplicity and flexibility that they offer to their end users with the capability of producing customized plastic parts, the proposed process has the ability to do the same but with metal parts. There is an ever growing market for metal parts, and if a technology can deliver the same high quality at a cheaper cost, then it would become the next big thing in the field of rapid prototyping. The applications can range from small bespoke parts to large-scale functional products that can be used without any post-processing.

The process can easily solder tough metals like aluminium that have a very tenacious oxide layer with the use of a special solder paste. As an extension of this research work, aluminium foil of $70-\mu \mathrm{m}$ thickness has been soldered using this process.

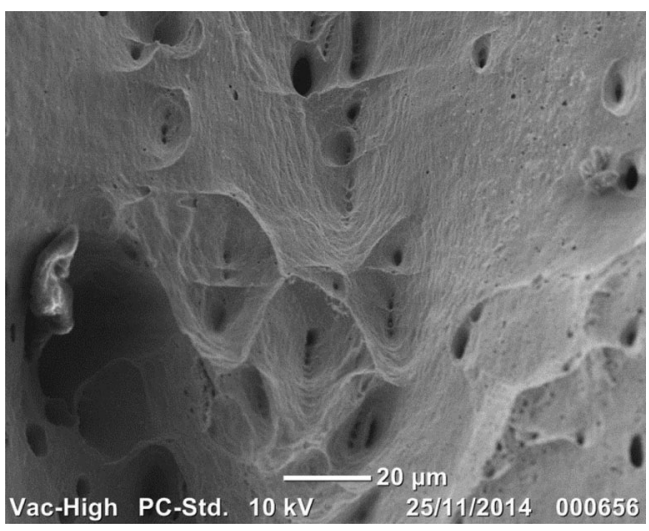

Fig. 15 Fracture mode of copper at $\times 800$ 
Fig. 16 Fracture mode. a Layers at $\times 800$ and $\mathbf{b}$ layer at $\times 3000$

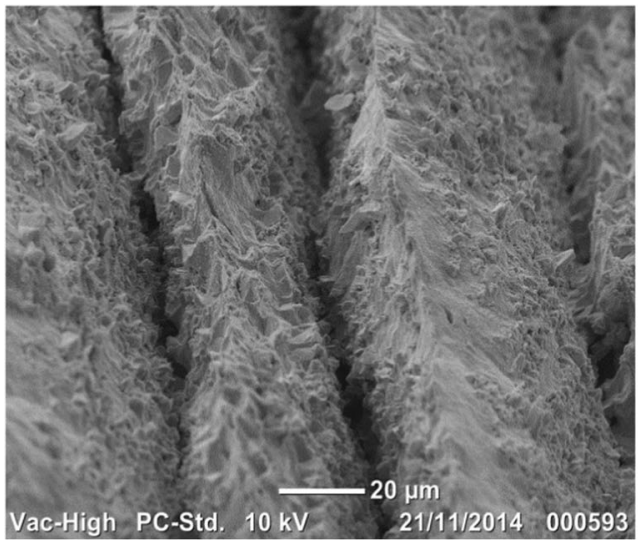

a

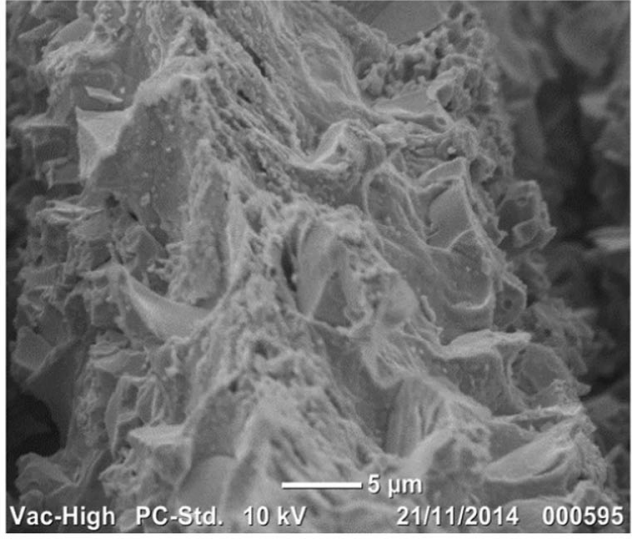

b
This goes to show the flexibility of the process dealing with varying thicknesses that could be used to produce a variety of metal products. It also has the capability to manufacture multiple layered material parts that could offer alternatives to the conventional metal products. Complex geometries with good mechanical properties are easily produced using CMFM. Figure 17 shows a 7 -mm-thick spanner with holes for hanging produced by CMFM of aluminium 1050 foils alongside a spanner produced by conventional methods. It is evident from the pictures that the spanner produced by CMFM has good surface finish and the layers are properly aligned together resulting in a good quality product.

This process can have a massive impact as it has reduced the limitations related to the production of metal parts. It can use any metal of any thickness, has the capability to produce multiple material parts, can easily attract the general public, does not require any post-processing to improve mechanical properties, has a shorter production time compared to its rival
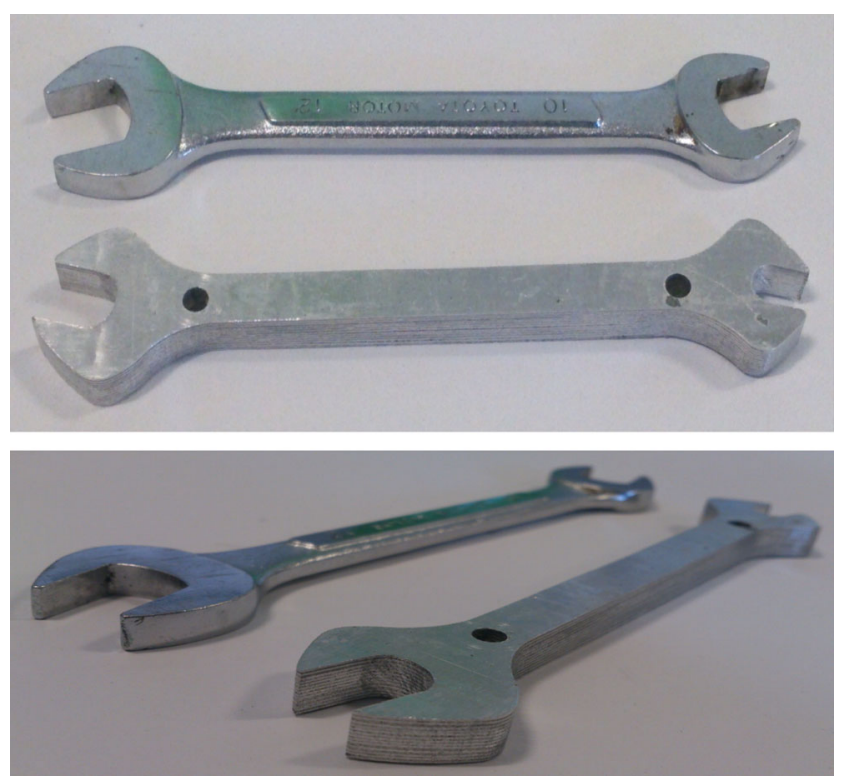

Fig. 17 Spanner produced by CMFM technologies, etc. In terms of processing time, CMFM is very effective. A general product like the spanner shown in Fig. 17 with a thickness of $7 \mathrm{~mm}$ would take $20 \pm 3 \mathrm{~min}$, and it will be ready to use after this time. On the other hand, the same product in a DMLS machine would take more than an hour$15 \mathrm{~min}$ to fill the machine chamber with an inert gas, $5 \mathrm{~min}$ mounting and levelling the build platform and $10 \mathrm{~min}$ for part production, with another 30 to 40 for cleaning up after and setting up for the next batch. It could be argued that DMLS can produce multiple parts in the same build, but the same is also possible for CMFM. In DMLS, the laser sinters the metal powder in to the desired products layer by layer. For CMFM, the laser can cut the required geometry on the platform side by side and the products can then be heated to produce the products. The process of DMLS spends a substantial amount of time for the initial setting and final powder removal. The laser also works slowly as it is required to sinter the metallic powder into the desired shape. CMFM required initial setting like levelling of the platform, but there is minimal postprocessing and the laser moves much more quickly as it is only cutting the outline profile of thin metal sheets [22].

\section{Conclusions}

The experimental results validate the integrity of the proposed process and show that it has the capability to challenge the existing metal prototyping technologies. The lap-shear tests proved that the bond between the layers is stronger than the material itself. It was always the parent metal that fractured and not the bonded area. The peel test consolidated this further with similar concluding results. However, in some specimens, peeling was observed with the formation of teeth-like ends while some broke off right where the bonded region started. Microstructural analysis showed good proportion of bonded area. The best example that could solidify CMFM as a strong candidate is the comparative tensile dog-bone test where the composite copper specimen showed more strength than the parent copper. This 
shows that the process has the capability to produce even stronger parts than the traditional machining methods.

Acknowledgments The authors would like to thank Anglia Ruskin University for providing the equipment and testing facilities to carry out the research.

Open Access This article is distributed under the terms of the Creative Commons Attribution 4.0 International License (http:// creativecommons.org/licenses/by/4.0/), which permits unrestricted use, distribution, and reproduction in any medium, provided you give appropriate credit to the original author(s) and the source, provide a link to the Creative Commons license, and indicate if changes were made.

\section{References}

1. Pham DT, Dimov SS (2001) Rapid manufacturing: the technologies and applications of rapid prototyping and rapid tooling. SpringerVerlag, London

2. Wohlers T (1999) Rapid prototyping and tooling - state of the industry. Wohlers Associates, Inc., Colorado

3. Magalhaes S (2003) Surface composition and microstructure control during pressure-less forming and sintering of ferrous powder metallurgy materials. Ph.D. thesis, Department of Materials Science and Engineering, Chalmers University, Goteborg, Sweden.

4. German RM (1996) Sintering theory and practice. John Wiley, New York

5. German RM (1994) Powder metallurgy science, 2nd edn. Metal Powder Industries Federation, Princeton, New Jersey

6. Abe F, Osakada K, Shiomi M, Uematsu K, Matsumoto M (2001) The manufacturing of hard tools from metallic powders by selective laser melting. J Mater Process Technol 111:210-213

7. ASM Metals Handbook (1985) Heat Treating, 9th edition, Vol. 4. American Society for Metals, Metals Park, OH, pp. 763-74.

8. ASM Metals Handbook (1985) Properties and Selection: Stainless Steels, Tool Materials and Special-Purpose Metals, 9th edition, Vol. 3. American Society for Metals, Metals Park, OH, pp. 893-99.
9. Bourell D, Wohlert M, Harlan N, Das S, Beaman J (2002) Powder densification maps in selective laser sintering. Adv Eng Mater 9(4): 663-669

10. Cormier D, Harrysson O, West H (2002) Characterization of H13 steel produced via electron beam melting. Rapid Prototyp J 10(1): 35-41

11. Prechtl M, Pursche L, Otto A (2004) System Technology and data Preparation for Automated Laser Assisted Stacking of Metal Foil. In: Proceedings of the 4th International Conference on Laser Assisted Net Shape Engineering - LANE, Baberg, Meisenbach Verlag, pp. 601-610.

12. Prechtl M, Otto A, Geiger M (2005) Rapid tooling by laminated object manufacturing of metal foil. queryTrans Tech 6-8:303-312

13. Butt J, Mebrahtu H, Shirvani H (2014) A novel rapid prototyping process for the production of metal parts. In: Proceedings of the Second International Conference on Advances in Civil, Structural and Mechanical Engineering - CSM, Birmingham, United Kingdom, pp. 26-29. doi: 10.15224/ 978-1-63248-054-5-45

14. BS EN 1465: 2009, Adhesives - Determination of tensile lapshear strength of bonded assemblies.

15. BS EN ISO 11339:2010, Adhesives - T-peel test for flexible-toflexible bonded assemblies.

16. PD CEN ISO/TR 16060:(2014), Destructive tests on welds in metallic materials - Etchants for macroscopic and microscopic examination.

17. BS EN ISO 6892-1 (2009) Metallic materials - Tensile testing, Part 1: Method of test at ambient temperature.

18. BS EN ISO 10365 (1995) Adhesives - Designation of main failure patterns.

19. Anglia Polytechnic University, Hassan Shirvani (2000) Honeycomb structure, method of forming a honeycomb structure and method of joining aluminium or aluminium alloy bodies. GB Patent: WO0033997 (A1).

20. Syvanen T (1996) Direct sintering of metals material and process development. M. Sc. Thesis, Tampere University of Technology.

21. McDonald JA, Ryall CJ, Wimpenny DI (2001) Rapid prototyping casebook. Professional Engineering Publishing Limited, London

22. Kotila J (1998) Development of steel based metal powder for DMLS-process. M. Sc. Thesis, Tampere University of Technology. 